\title{
MicroRNA-20 induces methylation of hepatitis B virus covalently closed circular DNA in human hepatoma cells
}

\author{
IN YOUNG MOON $^{1}$, JAE HEE CHOI ${ }^{1}$, JUNG WHA CHUNG ${ }^{1}$, EUN SUN JANG ${ }^{1}$, \\ SOOK-HYANG JEONG ${ }^{1,2}$ and JIN-WOOK KIM ${ }^{1,2}$ \\ ${ }^{1}$ Department of Medicine, Seoul National University Bundang Hospital, Seongnam, Gyeonggi 13620; \\ ${ }^{2}$ Department of Internal Medicine, Seoul National University College of Medicine, Seoul 03080, Republic of Korea
}

Received January 3, 2019; Accepted May 22, 2019

DOI: $10.3892 / \mathrm{mmr} .2019 .10435$

\begin{abstract}
Methylation was suggested to suppress the transcriptional activity of hepatitis B virus (HBV) covalently closed circular DNA (cccDNA) in hepatocytes. This may be associated with its low replicative activity during the inactive stage of chronic HBV infection; however, the exact mechanisms of methylation in HBV infection remain unknown. We have previously shown that short hairpin RNAs induced the methylation of the HBV genome in hepatoma cell lines. We also reported that the microRNA (miR) 17-92 cluster negatively regulates HBV replication in human hepatoma cells. In addition, miR-20a, a member of the miR 17-92 cluster, has sequence homology with the short hairpin RNA that induces HBV methylation. In the present study, we investigated whether miR-20a can function as an endogenous effector of HBV DNA methylation. The results indicated that overexpression of miR-20a could suppress the replicative activity of HBV and increased the degree of methylation of HBV cccDNA in the HepAD38 hepatoma cell line. Argonaute (AGO)1 and AGO2, effectors of the RNA-induced silencing complex, were detected in the nucleus of HepAD38 cells; however, only AGO2 was bound to HBV cccDNA. In addition, intranuclear AGO2 was determined to be bound with miR-20a. In conclusion, miR-20a may be loaded onto $\mathrm{AGO}$, prior to its translocation into the nucleus, inducing the methylation of HBV DNA in human hepatoma cells, leading to the suppression of HBV replication.
\end{abstract}

Correspondence to: Professor Jin-Wook Kim, Department of Medicine, Seoul National University Bundang Hospital, 82 Gumi-ro 173 Beon-gil, Bundang, Seongnam, Gyeonggi 13620, Republic of Korea

E-mail:kimjw@snubh.org

Abbreviations: HBV, hepatitis $\mathrm{B}$ virus; cccDNA, covalently closed circular DNA; miR, microRNA; AGO, Argonaute; RISC, RNA-induced silencing complex; DNMT, DNA methyltransferase; RdDM, RNA-directed DNA methylation; ChIP, chromatin immunoprecipitation; RNP-IP, ribonucleoprotein immunoprecipitation

Key words: HBV, methylation, miR, AGO, cccDNA

\section{Introduction}

Hepatitis B virus (HBV) poses global health burden by infecting $>250$ million people worldwide (1). Although the global prevalence of acute HBV infection is decreasing due to effective immunization, the prevalence chronic hepatitis B (CHB) and other HBV-associated chronic liver diseases have not reduced during the past decade (2). One of the main challenges in HBV eradication is the persistence of the viral minichromosome, also known as covalently closed circular DNA (cccDNA) which can stably remain in the nucleus of infected hepatocytes even after prolonged effective antiviral therapy $(3,4)$. Thus, HBV cccDNA has emerged as the main target molecule for the complete cure of chronic HBV infection (5).

The natural course of CHB has characteristic stages with respect to viral loads and hepatic inflammation: The initial immune tolerant phase with high viral loads and normal hepatic inflammation markers is followed by an immune clearance phase with a flare of hepatic inflammation and decrease in viral DNA levels; finally, the immune control phase with low or undetectable circulating viral loads ensues $(6,7)$. A progressive decrease in the serum HBV viral loads may be attributed to reductions in the amount of nuclear HBV cccDNA; however, HBV cccDNA persists throughout the natural course of $\mathrm{CHB}$, even in patients with complete virologic and serologic clearance, suggesting that the viral productivity of HBV cccDNA may decrease over time $(4,7)$. In addition, analysis of intrahepatic HBV RNA levels has revealed the transcriptional activity of cccDNA to decrease in the immune control phase of CHB $(8,9)$. The transcriptional activity of HBV cccDNA is modulated by a variety of non-specific and liver-specific transcription factors (8). Additionally, epigenetic modifications of HBV cccDNA, such as histone modifications and methylation of HBV cccDNA may also affect cccDNA transcription (10-12). Previously, studies by our group and other researchers have reported that the methylation of HBV cccDNA contributes to the transcriptional control of HBV cccDNA in CHB (13-15); however, the underlying mechanism by which the HBV cccDNA is methylated is yet to be elucidated.

MicroRNAs (miRNAs/miRs) regulate mammalian gene expression at the post-transcriptional level by directing 
RNA-induced silencing complex (RISC) to complementary mRNA targets, and subsequently inducing translational repression and/or mRNA destabilization $(16,17)$. miRNAs may also regulate gene expression at the transcriptional level indirectly by modifying the expression of DNA methyltransferases (DNMTs) $(18,19)$. In plants, miRNAs directly induce transcriptional silencing via DNA methylation by recruiting Argonaute (AGO)-containing effector complexes to the target DNA (20-24). Whether miRNAs can directly induce transcriptional silencing in mammalian cells remains unknown; however, similar miRNA machineries may also function, analogous to RNA-directed DNA methylation (RdDM) by small interfering RNA $(25)$ or Piwi-interacting small RNA $(26,27)$ in mammalian cells.

Our previous study demonstrated that short hairpin RNA induced the methylation of HBV cccDNA in hepatoma cells (28). Interestingly, the target sequence of the short hairpin RNA overlaps with the potential target site of Homo sapiens-miR-20a, a member of the oncogenic miR-17-92 cluster (29-31). In addition, our previous report has shown that the miR-17-92 cluster negatively regulates HBV replication in human hepatoma cells (32), and the HBV X sequence exhibited conserved homology to miR-20a across HBV genotypes (Fig. 1).

Considering the structural homology between short hairpin RNAs and miRNA precursors, we hypothesized that miR-17-92 may also induce the methylation of HBV cccDNA. To investigate this hypothesis, miR-17-92 precursors were transfected into human hepatoma cells and the methylation profiles of the HBV genome were determined.

\section{Materials and methods}

In vitro $H B V$ replication model and isolation of $H B V$ cccDNA. HepAD38 cells that support HBV replication under the control of a tetracycline-inducible promoter (a generous gift from Professor C. Seeger (Fox Chase Cancer Center, Philadelphia, PA, USA) were used (33). HBV replication was induced by omitting tetracycline from the DMEM/F12 culture medium (Welgene, Inc., Gyeongsan, South Korea) for 5-7 days. All cells were maintained in $5 \% \mathrm{CO}_{2}$ at $37^{\circ} \mathrm{C}$. $\mathrm{HBV}$ cccDNA was purified as previously reported (28), precipitation of protein-bound DNA was omitted to allow the utilization of both the protein-free and protein-bound form of cccDNA. Briefly, HepAD38 cells were lysed by the addition of $0.4 \mathrm{ml}$ of cell lysis buffer [50 mM Tris-HCl (pH 8.0), 1 mM EDTA, $0.2 \%(\mathrm{v} / \mathrm{v})$ Nonidet P-40 and $0.15 \mathrm{M} \mathrm{NaCl}$. The lysate was centrifuged at $16,000 \mathrm{xg}$ at $4^{\circ} \mathrm{C}$ for $2 \mathrm{~min}$, and the supernatant (cytoplasmic fraction) was collected for the extraction of HBV relaxed circular DNA (rcDNA, described below). The pellet of the nuclear fraction was treated with the same volume of nuclear lysis buffer $(6 \%$ SDS, $0.1 \mathrm{~N} \mathrm{NaOH})$ at $37^{\circ} \mathrm{C}$ for $15 \mathrm{~min}$, followed by phenol extraction using an volume of phenol-chloroform-isoamyl alcohol mixture (Sigma-Aldrich; Merck KGaA, Darmstadt, Germany) and ethanol-precipitation with double the volume of absolute alcohol (Sigma-Aldrich; Merck KGaA). Contaminating genomic DNA was removed using Plasmid-Safe DNase (Epicentre Biotechnologies, Madison, WN, USA), according to the manufacturer's instructions, and the absence of contaminating genomic DNA was confirmed by the negative PCR results obtained using a primer pair for $\beta$-globin: Forward, 5'-GTGCACCTGACTCCT GAGGAGA-3' and reverse, 5'-CCTTGATACCAACCTGCC CAG-3'.

Overexpression of the miR-17-92 cluster. Plasmids expressing human miRNA precursor were purchased from OriGene Technologies, Inc. (Rockville, MD, USA): pCMV-MIR control (6.2 kb, cat. no. PCMVMIR), pCMV-MIR 17-5p (6.3 kb, cat.no. SC400201), pCMV-MIR18a (6.3 kb, cat. no. SC400218), pCMV-MIR19a (6.3 kb, cat. no. SC400253), pCMV-MIR20a (6.3 kb, cat. no. SC400269) and pCMV-MIR92a (6.3 kb, cat. no. SC400682). Plasmids were transfected into HepAD38 cells using Lipofectamine ${ }^{\circledR} 2000$ (Thermo Fisher Scientific, Inc., Waltham, MA, USA) at a concentration of $10 \mu \mathrm{g}$ per $60 \mathrm{~mm}$ dish, according to the manufacturer's instruction (Thermo Fisher Scientific, Inc.). Following transfection, the cells were incubated at $37^{\circ} \mathrm{C}$ in $5 \% \mathrm{CO}_{2}$ for 5 days prior to analysis for $\mathrm{HBV}$ replication and methylation as described below.

Quantification of cytoplasmic HBV DNA by quantitative (q) PCR and Southern blotting. HepAD38 cells grown on a $60-\mathrm{mm}$ culture dish at a density of $5 \times 10^{5}$ cells $/ \mathrm{ml}$ in $4 \mathrm{ml}$ medium were lysed and nuclei were pelleted as previously reported (34). The cytoplasmic fraction was treated with $1 / 4$ volume of $35 \%$ PEG 8000 in $1.75 \mathrm{M} \mathrm{NaCl}$, incubated on ice for $30 \mathrm{~min}$ and centrifuged at $16,000 \mathrm{x} \mathrm{g}$ for $10 \mathrm{~min}$ at $4{ }^{\circ} \mathrm{C}$. The pelleted HBV core particles were dissolved in proteinase K buffer [10 mM Tris- $\mathrm{HCl}(\mathrm{pH} 8.0), 100 \mathrm{mM}$ $\mathrm{NaCl}, 1 \mathrm{mM}$ EDTA, $0.5 \%$ SDS, $200 \mu \mathrm{g} / \mathrm{ml}$ proteinase K] and incubated at $45^{\circ} \mathrm{C}$ for $1 \mathrm{~h}$. The core-associated rcDNA was recovered by phenol extraction and ethanol precipitation as aforementioned.

qPCR was performed as previously reported to quantify HBV rcDNA (35). PCR amplification was performed using $\mathrm{SYBR}^{\circledR}$ Green (Enzynomics, Inc., Daejeon, South Korea) and the following primer pair, at final concentration of $200 \mathrm{nM}$, was sued to amplify nucleotides 2,268-2,286 (Genbank accession number AF286594): Forward, 5'-GAGTGTGGATTC GCACTCC-3' and reverse, 5'-GAGGCGAGGGAGTTCTTC T-3'. The Thermal Cycler Dice Real Time System (Takara Bio, Inc., Otsu, Japan) was used according to the manufacturer's instructions. The thermocycling conditions of qPCR comprised an initial denaturing step at $95^{\circ} \mathrm{C}$ for $15 \mathrm{~min}$, followed by 45 amplification cycles at $95^{\circ} \mathrm{C}$ for $10 \mathrm{sec}, 60^{\circ} \mathrm{C}$ for $20 \mathrm{sec}, 72^{\circ} \mathrm{C}$ for $30 \mathrm{sec}$. Mitochondrial DNA was amplified with the following primers and used for normalization: Forward, 5'-GCCTGCCTGATCCTCCAAAT-3' and reverse, 5'-AAGGTAGCGGATGATTCAGCC-3'.

Southern blotting for the analysis of HBV rcDNA was performed as previously reported (13). Briefly, $15 \mu \mathrm{g}$ of HBV rcDNA was electrophoresed on a $1 \%$ agarose/Tris-Borate EDTA gel, followed by partial depurination with $\mathrm{HCl}(0.25 \mathrm{M})$ for $15 \mathrm{~min}$ and denaturation in $\mathrm{NaOH}(0.5 \mathrm{M})$ for $15 \mathrm{~min}$. DNA was transferred in 20X standard saline citrate (SSC) buffer to a Hybond-N+ membrane (Roche Diagnostics GmbH, Mannheim, Germany) by capillary blotting. The membrane was UV-cross-linked and hybridized with digoxygenin-tagged HBV RNA probes in Dig Easy Hybridization Buffer (20 ng/ml 
stock diluted 1:5,000; Roche Diagnostics GmbH, Mannheim, Germany;) overnight at $60^{\circ} \mathrm{C}$. Following hybridization, the membrane was washed twice for $5 \mathrm{~min}$ at room temperature in $2 \mathrm{X} \mathrm{SSC}, 0.1 \% \mathrm{SDS}$ and twice for $15 \mathrm{~min}$ at $60^{\circ} \mathrm{C}$ in $0.1 \mathrm{X}$ SSC and $0.1 \%$ SDS. The membrane was blocked with blocking reagent (Roche Diagnostics $\mathrm{GmbH}$ ) for $30 \mathrm{~min}$ at room temperature and incubated for $30 \mathrm{~min}$ in blocking buffer containing $187.5 \mathrm{mU} / \mathrm{ml}(1: 4,000 \mathrm{v} / \mathrm{v})$ anti-digoxigenin-alkaline phosphatase (AP; Roche Diagnostics $\mathrm{GmbH}$ ). The membrane was treated with Immun-Star AP Substrate (Bio-Rad Laboratories, Inc., Hercules, CA, USA) and was exposed to X-ray film for $1 \mathrm{~h}$. In order to estimate the viral productivity of cccDNA, the loading amounts of HBV DNA were normalized by the copy numbers of HBV cccDNA determined by RT-qPCR as previously reported (36). Densitometry analysis was performed using Quantity One software (version 4.6.2; Bio-Rad Laboratories, Inc.).

Quantification of cytoplasmic HBV pregenomic RNA (pgRNA) using reverse transcription $(R T)-q P C R$ and dot blot analysis. Total RNA was extracted from the cytoplasmic fraction of HepAD38cells using AccuZol reagent (Bioneer Corp., Daejon, South Korea), according to the manufacturer's instructions, and treated with $5 \mathrm{U} / \mu \mathrm{l}$ DNase (Takara Bio, Inc., Otsu, Japan). RT was performed using $10 \mu \mathrm{g}$ of total RNA and random hexamers with MMLV (iNtRON Biotechnology, Seongnam, South Korea) as recommended. RT was performed using the following thermocycling conditions: $65^{\circ} \mathrm{C}$ for $5 \mathrm{~min}, 4^{\circ} \mathrm{C}$ for $5 \mathrm{~min}, 25^{\circ} \mathrm{C}$ for $10 \mathrm{~min}, 37^{\circ} \mathrm{C}$ for $50 \mathrm{~min}, 85^{\circ} \mathrm{C}$ for $5 \mathrm{~min}$ and $37^{\circ} \mathrm{C}$ for $20 \mathrm{~min}$. qPCR was then performed with the same primers for rcDNA amplification, with GAPDH used for normalization: Forward, 5'-GCACCGTCAAGGCTGAGA AC-3' and reverse, 5'-ATGGTGGTGAAGACGCCAGT-3'.

A dot blot assay was performed in a manner to Southern blotting. Briefly, $2 \mu \mathrm{g}$ of cytoplasmic RNA was obtained as aforementioned and was denatured using $1 \mathrm{M} \mathrm{NaOH}$ and fixed on the Hybond-N+ membrane by microwave heating for $2 \mathrm{~min}$. Hybridization and signal detection with digoxygenin-tagged HBV RNA probe was performed as described for Southern blotting.

RNA stability assay. Actinomycin D ( $5 \mu \mathrm{g} / \mathrm{ml}$, Sigma-Aldrich; Merck KGaA) was added to the culture medium of HepAD38 cells to block transcription at $24 \mathrm{~h}$ following transfection of miRNA mimics (125 nmol). Total RNA was extracted at 1, 3 and $6 \mathrm{~h}$ following actinomycin $\mathrm{D}$ treatment under the aforementioned culture condition and $\mathrm{HBV}$ pgRNA was measured by RT-qPCR as aforementioned.

Assessment of HBV cccDNA methylation by methylationspecific PCR and bisulfite sequencing. HBV cccDNA was isolated as described above and subjected to bisulfite modification using the Imprint DNA Modification Kit according to the manufacturer's instructions (MOD50; Sigma-Aldrich; Merck KGaA Darmstadt, Germany). The primers for methylation-specific PCR were designed based on the universal $\mathrm{CpG}$ island II sequence of HBV (37) by using Methyl Biosystems Primer Express (v1.0, Applied; Thermo Fisher Scientific, Inc.): Nonmethylation forward, 5'-GTGGGATGTTTTTTG TTTAT 3', reverse, 5'-ACAAAATACACACAATCCCAA-3'; methylation forward, 5'-GCGGGACGT TTT TTGTTT AC-3' and methylation reverse, 5'-ACGAAATACACACGA TCCGA-3' at final concentration of $200 \mathrm{nM}$. The C1000 ${ }^{\mathrm{TM}}$ Thermal Cycler (Bio-Rad Laboratories, Inc., Hercules, CA, USA) was used, according to the manufacturer's instructions. The thermocycling conditions for qPCR comprised initial denaturation at $95^{\circ} \mathrm{C}$ for $15 \mathrm{~min}$, followed by 45 amplification cycles at $95^{\circ} \mathrm{C}$ for $10 \mathrm{sec}, 55^{\circ} \mathrm{C}$ for $20 \mathrm{sec}$ and $72^{\circ} \mathrm{C}$ for $30 \mathrm{sec}$. Bisulfite sequencing was also performed by PCR-based TA cloning of bisulfite-modified HBV cccDNA CpG island II as previously reported (28). Briefly, the PCR product were purified by AccuPrep ${ }^{\circledR}$ PCR Purification Kit (Bioneer Corporation, Daejeon, South Korea) and 50 ng of purified DNA was ligated with $50 \mathrm{ng}$ of pDrive cloning vector (Qiagen $\mathrm{GmbH}$ ). Bisulfite sequencing was performed using the $\mathrm{T} 7$ promoter primer: 5'-TAATACGACTCACTATAGGG-3'.

Chromatin immunoprecipitation (ChIP) and ribonucleoprotein immunoprecipitation. The association of AGO with HBV cccDNA was assessed using ChIP $(38,39)$. Briefly, plasmids expressing FLAG-AGO1 and FLAG-AGO2 protein (Addgene plasmid cat. no. 21533 and 21538, respectively; Addgene, Inc., Cambridge, MA, USA; gifts from Professor Edward Chan, University of Florida) (40) were transfected into HepAD38 cells as aforementioned. On day 5, cells were cross-linked using $1.42 \%$ formaldehyde for $15 \mathrm{~min}$ at room temperature. Nuclei were isolated and sonicated as described (38). Chromatin samples, $100 \mu \mathrm{g}$ in $100 \mu \mathrm{l}$ of dilution buffer $(0.01 \%$ SDS, 1.1\% TritonX-100, $1.2 \mathrm{mM}$ EDTA, $16.7 \mathrm{mM}$ Tris/HCl, $\mathrm{pH} 8.0,167 \mathrm{mM} \mathrm{NaCl}$ ), were treated with either $8 \mu \mathrm{g}$ of anti-FLAG M2 antibody (cat. no. F1804, Sigma-Aldrich; Merck KGaA) or normal mouse IgG (cat. no. sc-2025, Santa Cruz Biotechnology, Inc., Dallas, TX, USA) as a control, with rotation for $10 \mathrm{~min}$ at room temperature and then pre-incubated with Dynabeads Protein G (Thermo Fisher Scientific, Inc.) as recommended. Following several steps of washing, Chelex100 (cat. no. 142-1253, Bio-Rad Laboratories, Inc.) slurry was added directly to the washed beads (39). DNA was eluted by boiling the Chelex slurry, and HBV cccDNA was detected using the following primers by qualitative PCR: Forward, 5' CTGAATCCCGCGGACGACCC-3' and reverse, 5'-ACCCAAGGCACAGCTTGGAGG-3' at final concentration of $200 \mathrm{nM}$ after treatment with Plasmid-safe DNase. The thermocycling conditions for PCR comprised of an initial denaturation at $95^{\circ} \mathrm{C}$ for $5 \mathrm{~min}$, followed by 35 cycles at $94^{\circ} \mathrm{C}$ for $1 \mathrm{~min}, 60^{\circ} \mathrm{C}$ for $1 \mathrm{~min}, 73^{\circ} \mathrm{C}$ for $1 \mathrm{~min}$ and a final extension of $73^{\circ} \mathrm{C}$ for $5 \min (41)$.

The presence of the nuclear AGO-miR complex was assessed by ribonucleoprotein immunoprecipitation (RNP-IP). Briefly, $5 \mu \mathrm{g}$ of plasmid expressing FLAG-AGO2 protein was co-transfected along with $10 \mu \mathrm{g}$ of either pCMV-MIR control or pCMV-MIR20a plasmid into HepAD38 cells using Lipofectamine ${ }^{\circledR} 2000$ as aforementioned. On day 5, cells were harvested and cross-linked as described previously (42). RNase Out (final concentration $100 \mathrm{U} / \mathrm{ml}$, cat. no. 10777019, Thermo Fisher Scientific, Inc.) and dithiothreitol (final concentration $1 \mathrm{mM}$ ) were added to the nuclear fraction of samples as described (38). Nuclear RNA was released from cross-linked proteins by digestion with $200 \mu \mathrm{g} / \mathrm{ml}$ proteinase K (Takara Bio, Inc., Seoul, 

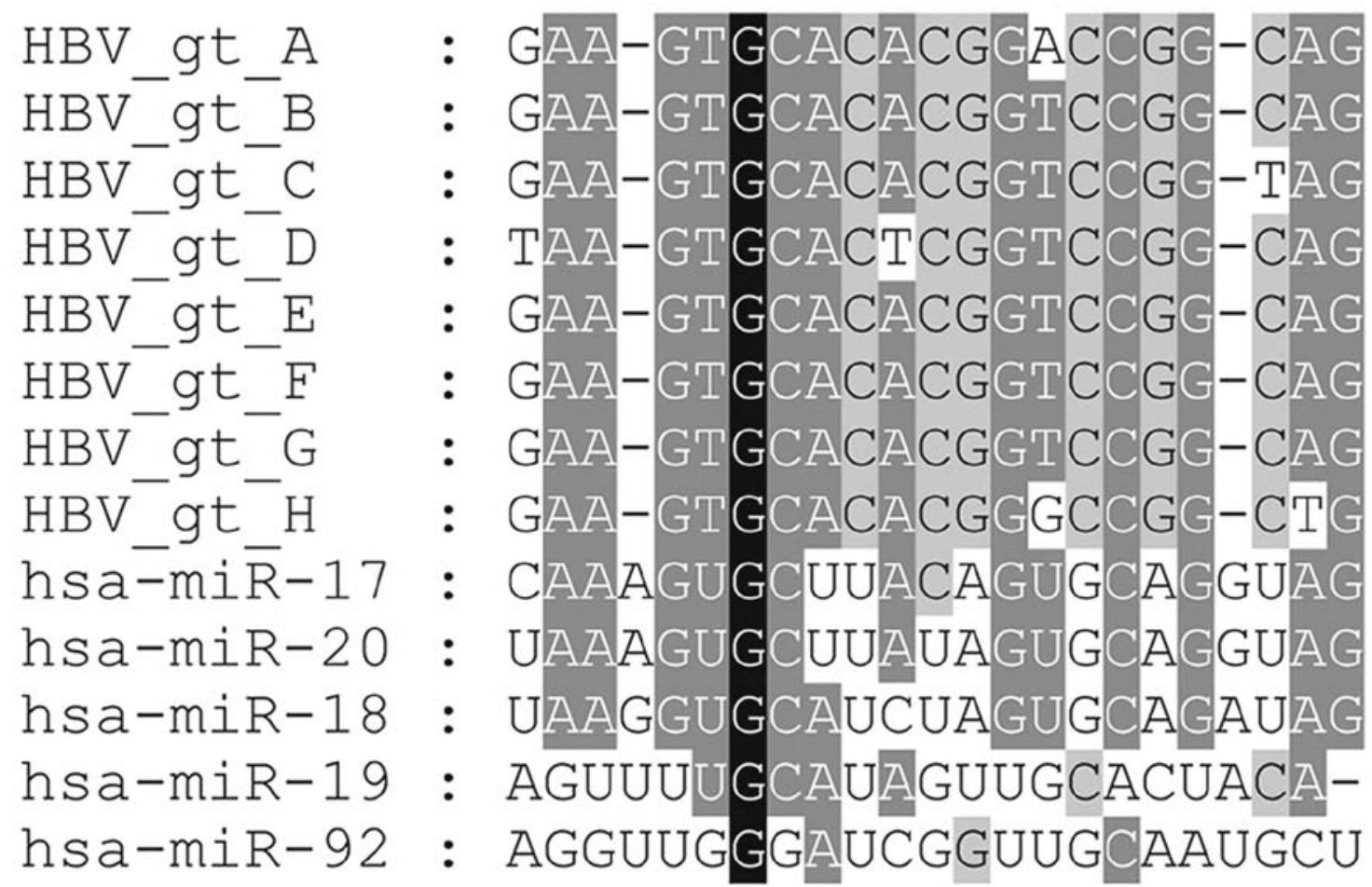

Figure 1. Alignment of HBV and miR-17-92 cluster miRs. Hepatitis B sequences present nucleotides 1,567-1,587 on the X gene of each genotype. Black, dark gray and light gray shades indicate 100, 80 and 60\% match with conserved sequence, respectively. HBV, hepatitis B virus; hsa, Homo sapiens; miR, microRNA.

South Korea) for $1 \mathrm{~h}$ at $55^{\circ} \mathrm{C}$, followed by TRIzol ${ }^{\circledR}$ extraction (Thermo Fisher Scientific, Inc.). Stem-loop RT-qPCR was performed to detect miR-20a with primers designed as reported (43): Stem-loop RT primer, 5'-GTCGTATCCAGT GCAGGGTCCGAGGTATTCGCACTGGATACGACCTAC CT-3'; miR-20 forward, 5'-ACACTCCAGCTGGGTAAA GTGCTTAT-3' and reverse, 5'-CCAGTGCAGGGTCCG AGGTA-3'. RT was performed using $0.2 \mu \mathrm{g}$ of total RNA and stem loop RT primer (50 nM), dNTPs (250 nM each), MMLV (200 U/ml; Intron Biotechnology, Inc.), RNase inhibitor $(40 \mathrm{U} / \mathrm{ml}$; Intron Biotechnology, Inc) in RT buffer [10\% glycerol, $50 \mathrm{mM}$ Tris- $\mathrm{HCl}$ (pH 8.3), $3 \mathrm{mM} \mathrm{MgCl}, 20 \mathrm{mM}$ DTT and $75 \mathrm{mM} \mathrm{KCl}$ ] with the following thermocycling conditions: $16^{\circ} \mathrm{C}$ for $30 \mathrm{~min}, 42^{\circ} \mathrm{C}$ for $30 \mathrm{~min}$ and $85^{\circ} \mathrm{C}$ for $5 \mathrm{~min}$. The qPCR thermocycling conditions were as follows: Initial denaturation at $95^{\circ} \mathrm{C}$ for $10 \mathrm{~min}$, followed by 40 cycles at $60^{\circ} \mathrm{C}$ for $1 \mathrm{~min}$ and $95^{\circ} \mathrm{C}$ for $15 \mathrm{sec}$.

Statistical analysis. qPCR data of HBV rcDNA, HBV RNA and methylation-specific PCR were analyzed via the $2^{-\Delta \Delta C q}$ method (44). All samples were quantified in triplicate. At least three experiments were repeated and the results were presented as the mean \pm standard deviation. P-values were calculated by a pairwise fixed reallocation randomization test using REST software (Qiagen, Inc, Valencia, CA, Inc.) (45); $\mathrm{P}<0.05$ was considered to indicate a statistically significant difference.

\section{Results}

miR-20a suppresses the replication of $H B V$ cccDNA at the transcriptional level in HepAD38 cells. Our previous study showed that the miR-17-92 cluster negatively regulated HBV replication in human hepatoma cells (32). qPCR and Southern blotting indicated that miR-17-5p and miR-20a significantly reduced the levels of HBV DNA in HepAD38 cells (Fig. 2A and B). The reduction was associated with significantly suppressed HBV RNA levels (Fig. 2C and D). Analysis of RNA stability revealed that degradation of HBV RNA was not accelerated by miR-17-5p and miR-20a (Fig. 2E). miR-17-5p and miR-20a did not significantly affect the stability of HBV RNA, indicating that the miRs may act on the transcription of HBV RNA in a different manner other than affecting its stability.

miR-20a induces the methylation of HBV cccDNA in HepAD38 cells. Additionally, whether miR-17-5p and miR-20a induced the methylation of HBV cccDNA was determined as these two members of the miR-17-92 cluster were suggested to suppress the replication of $\mathrm{HBV}$ at the transcriptional level. Methylation-specific PCR revealed that overexpression of miR-17-5p and miR-20a induced a significant increase in the degree of methylation in HBV cccDNA compared with the control (Fig. 3A). Bisulfite sequencing revealed that the frequency of methylation induced by miR-17-5p did not significantly different from control $(\mathrm{P}=0.348)$, whereas miR-20a induced a significantly higher level of methylation in the putative target site of $\mathrm{HBV}$ cccDNA ( $\mathrm{P}=0.001$; Fig. 3B).

AGO2 translocates to the nucleus of HepAD38 cells and binds to $H B V$ cccDNA. In order to elucidate the mechanism underlying cccDNA methylation by miR-20a, we sought to determine whether AGOs, the main effectors of RISC, 
A
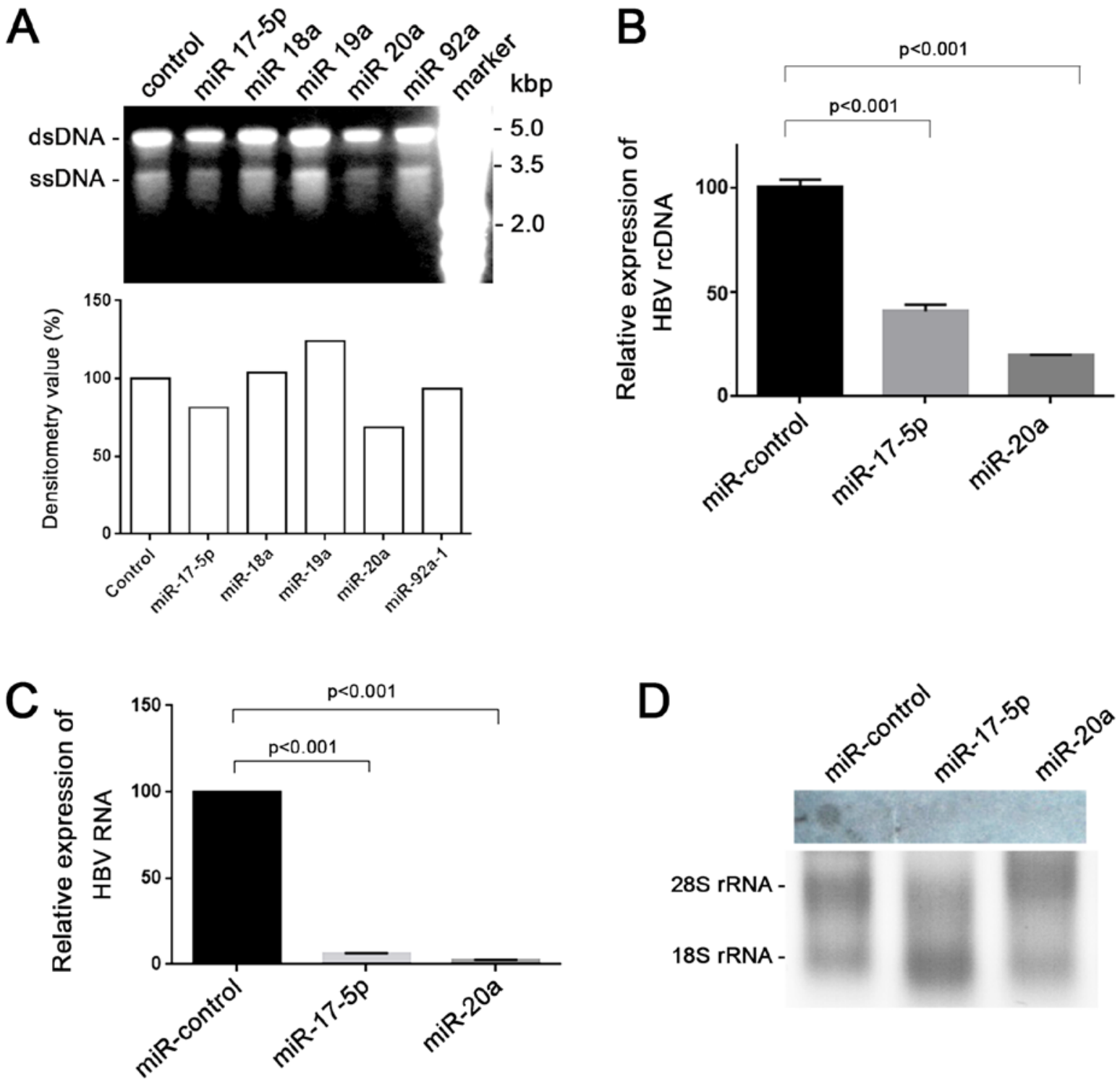

28S rRNA -

18S rRNA -

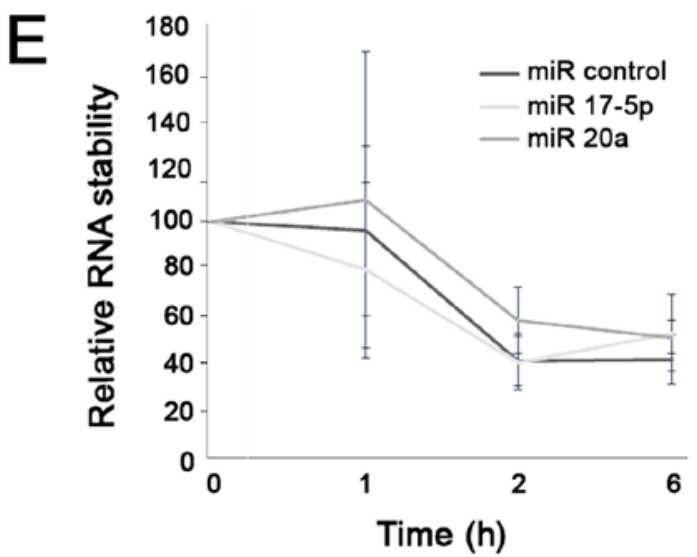

Figure 2. Overexpression of miR-17-5p and miR-20a suppresses HBV replication in HepAD38 cells. (A) Southern blotting analysis of cytoplasmic HBV rcDNA was performed after transfection of miR-17-92 precursor-expressing plasmids. Loading amounts were adjusted according to the copy numbers of HBV cccDNA as determined by qPCR. Therefore, the relative quantity of HBV DNA indicated the viral productivity per unit cccDNA. Compared with the control, miR-17-5p and miR-20a suppressed HBV replication by 18 and 32\%, respectively, as evaluated by densitometry analysis. The image used for densitometry analysis is representative of three independent experiments. (B) Cytoplasmic HBV rcDNA levels were determined by qPCR in HepAD38 cells transfected with miR-17-5p and miR-20a precursor-expressing plasmids. Error bars indicate standard deviation. (C) Cytoplasmic HBV RNA was measured by RT-qPCR in HepAD38 cells transfected with miR-17-5p and miR-20a precursor plasmids. The error bars indicate the standard deviation. (D) Dot blot assay of HBV RNA indicated the suppression of HBV RNA by miR-17-5p and miR-20a. (E) Analysis of HBV RNA stability in HepAD38 cells transfected with miR-17-5p and miR-20a precursor plasmids. Actinomycin D was added to culture medium and RNA was harvested at the time points as indicated. Error bars indicate standard deviation. dsDNA, double stranded DNA; HBV, hepatitis B virus; miR, microRNA; rcDNA, relaxed circular DNA; RT-qPCR, reverse transcription-quantitative polymerase chain reaction; ssDNA, single stranded DNA. 
A

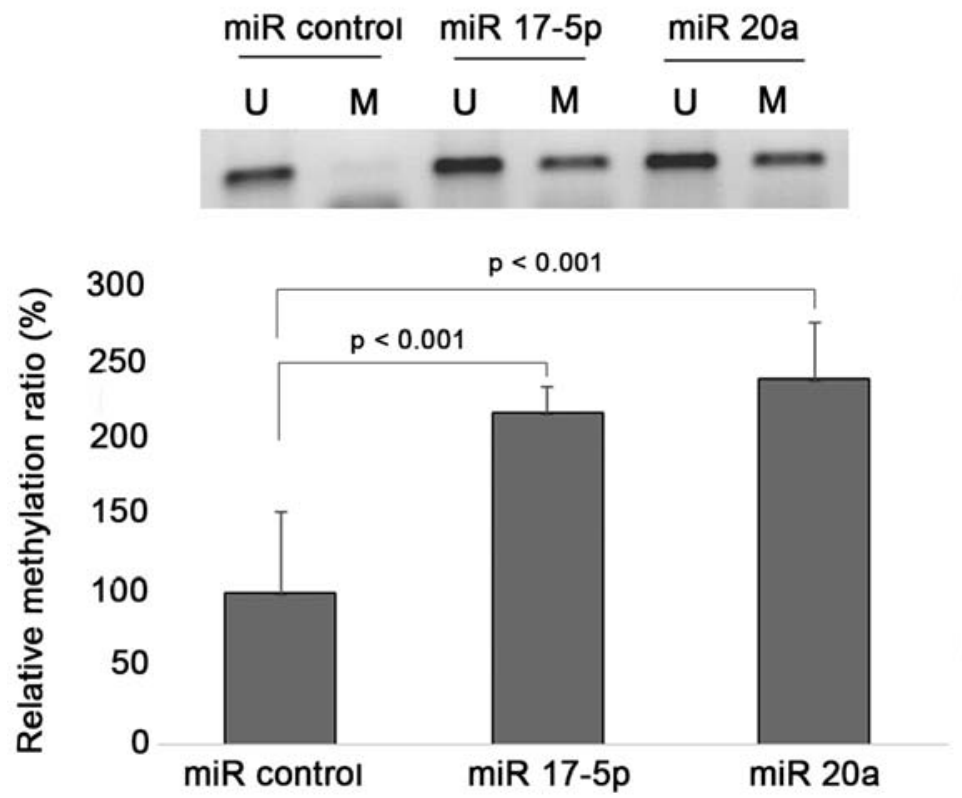

B

miR control

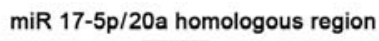

$\operatorname{miR} 17-5 p$

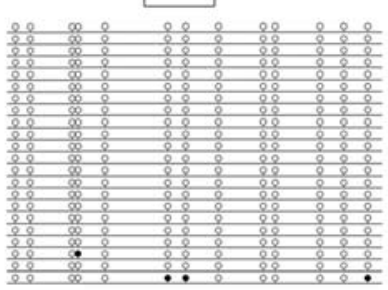

$\operatorname{miR} 20 a$
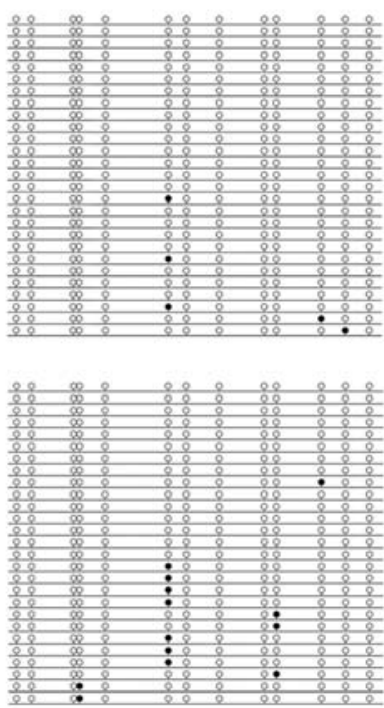

Figure 3. miR-20a induces the methylation of HBV cccDNA. (A) Methylation-specific PCR assay. HepAD38 cells were transfected with miRNA precursor-expressing plasmids and cccDNA was isolated at day 7 for bisulfite modification. Bisulfite-modified HBV cccDNA was amplified with methylation-specific PCR primer sets. (upper panel). The relative amount of methylated to unmethylated cccDNA was assessed (lower panel). The results are representative of three independent experiments; error bars indicate the standard deviation. (B) Bisulfite sequencing analysis of HBV cccDNA. CpG island II was amplified from bisulfite-modified HBV cccDNA, TA-cloned and sequenced. Metheylated and unmethylated CpG dinucleotides were marked by open and filled circles, respectively. Compared with the control, overexpression of miR-17-5p exhibited a similar level of methylation ( $\mathrm{P}=0.348)$, whereas miR-20a exhibited a significantly higher degree of methylation $(\mathrm{P}=0.001)$. cccDNA, covalently closed circular $\mathrm{DNA}$; miR, microRNA; $\mathrm{U}$, unmethylated primer set; M, methylated primer set; HBV, hepatitis B virus; PCR, polymerase chain reaction.

\section{A Chromatin immunoprecipitation}

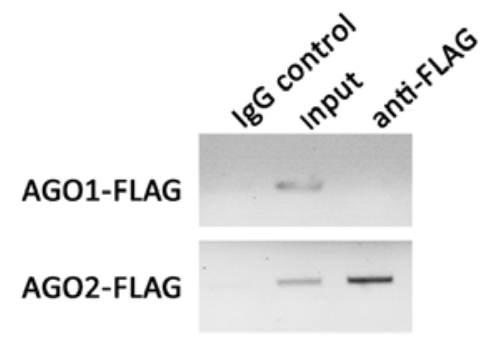

B RNA-immunoprecipitation

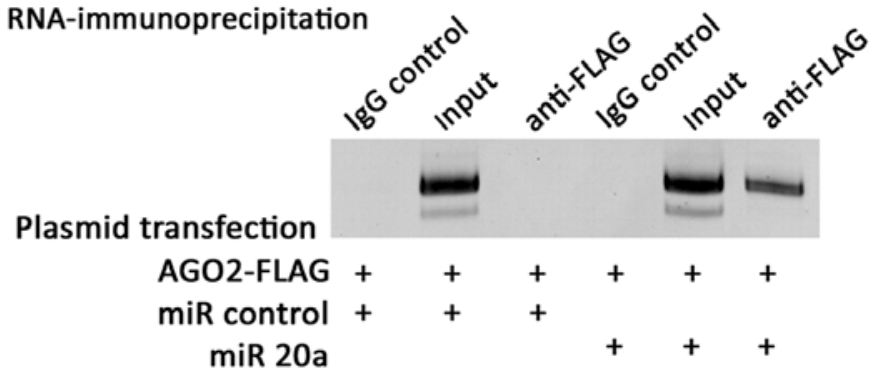

Figure 4. Nuclear AGO2 is associated with HBV cccDNA and miR-20a. (A) Chromatin immunoprecipitation analysis was performed using HepAD38 cells transfected with AGO1-FLAG (upper gel) or AGO2-FLAG plasmids (lower gel). Immunoprecipitated DNA was amplified with HBV cccDNA-specific primers. AGO1 did not bind HBV cccDNA (anti-FLAG lanes, upper gel), whereas AGO2 was associated with HBV cccDNA (anti-FLAG lanes, lower gel). The results were representative of three independent experiments. (B) ribonucleoprotein immunoprecipitation analysis was performed using HepAD38 cells transfected with AGO2-FLAG plasmid, along with an miR-20a-expressing plasmid. RNA was extracted from anti-FLAG immunoprecipitates and amplified for miR-20a. The results were representative of two independent experiments. AGO, Argonaute; miR, microRNA; HBV, hepatitis B virus.

are directed to nuclear HBV cccDNA. The ChIP assay showed that AGO1 and AGO2 were present in the nucleus (Fig. 4A, input lanes). On the contrary, AGO2 but not AGO1 was associated with HBV cccDNA (Fig. 4A).

Nuclear AGO2 associates with miR-20. As AGO2 was associated with nuclear HBV cccDNA, RNP-IP was performed to determine whether miR-20a interacts with intranuclear AGO2.
The results demonstrated that overexpression of miR-20a promoted interactions between miR-20a-bound AGO2 in the nuclei of HepAD38 cells (Fig. 4B).

\section{Discussion}

Although methylation has been identified in vitro $(13,28)$ and in vivo (13-15) as a mechanism of transcriptional regulation in 
HBV replication, how HBV cccDNA is methylated remains unknown. Our previous study showed that miR-20a interacts directly with the HBV X/polymerase gene sequence (32). The potential target sequence is also shared by a short hairpin RNA which was proposed to induce the methylation of HBV cccDNA (28). These findings prompted us to evaluate the epigenetic effect of miR-20a in the present study. The results indicated that human miR-20a may modulate the de novo methylation of nuclear HBV DNA in a hepatoma cell line. To the best of our knowledge, this is the first study to investigate methylation of the HBV genome by overexpressing miRNA.

RNA-directed transcriptional gene silencing (TGS) has been reported in mammalian cells by independent researchers $(25,46-48)$, but the underlying mechanisms have not yet been fully understood. Human miRNA is loaded onto RISC which includes Dicer, AGOs, TAR RNA binding protein and EMSY interactor protein (49), and miR-loaded RISC acts as an effector of slicer-dependent and slicer-independent post-transcriptional silencing (50). In addition, it has been reported that AGO1 and AGO2 are transported to the nuclear compartment in human cells (51). The detection of AGO2 and RNA interference factors in human nuclei suggests their participation in TGS (52-54). Additionally, the nuclear translocation of miR-bound $\mathrm{AGO} 2$ has been associated with gene silencing (55); $\mathrm{AGO} 2$ and miRNAs are recruited to the promoter region leading to TGS $(48,56)$. In the present study, miR-20a-loaded AGO2 was determined to translocate to the nucleus, which supports the hypothesis that TGS may occur via miR-bound $\mathrm{AGO} 2$.

Our data also demonstrated that AGO2 can bind to the nuclear HBV genome (cccDNA). This observation, along with the reported translocation of miR-20a-bound $\mathrm{AGO} 2$ into the nucleus, suggests that miR-20a may direct AGO/RISC to the homologous target of HBV DNA. We speculate that miR-guided AGO/RISC may function as an effector of de novo methylation in mammalian cells, in a manner analogous to RdDM in plants (57). HBV X protein (HBx) upregulates DNMT3 (58), which is the principal enzyme for mammalian de novo DNA methylation (59), and directs DNMT3 to target DNA (60). Based on this, we proposed that $\mathrm{HBV}$ cccDNA first binds to miR-guided AGO2-RISC, which in turn recruits HBX-mediated DNMT3 to AGO2-bound cccDNA. However, further investigation is required by studying the interaction between miR-20a-loaded RISC, DNMT3a HBx and HBV cccDNA.

RT-qPCR and hybridization assays in the present study indicated that miR-17-5p and miR-20a suppressed HBV RNA levels but did not affect RNA stability. These findings suggest that miR-induced methylation inhibits the transcription of HBV cccDNA. We previously reported that methylation suppressed the transcriptional activity of HBV cccDNA by an in vitro nuclear run-off assay (13). Bisulfite sequencing demonstrated that miR-17-5p markedly induced gene methylation. Since the miR-17-92 cluster was identified in mammalian nuclei (61-64), and the mature sequences of miR-17-5p and miR-20a differ by only two ribonucleotides, miR-17-5p may also induce methylation that could reduce the transcriptional activity of HBV cccDNA. This was indicated by the suppressed viral replication of DNA as observed by Southern blotting and the increased methylation observed by methylation-specific PCR.
The methylation of HBV cccDNA has been reported to contribute to the transcriptional suppression of HBV replication (13-15); however, the exact mechanisms of methylation are yet to be elucidated. The results of the present study may provide insight into the role of miRNAs as an innate epigenetic modulator in chronic HBV infection. Furthermore, our findings may improve understanding of the endogenous mechanisms of TGS in mammalian cells. As the persistence of HBV cccDNA is the major obstacle in curing chronic HBV infection $(4,65)$, these miRNA-induced epigenetic modifications may have therapeutic potential in the development of novel treatments against chronic hepatitis B.

Of note, there are several limitations of the present study to be addressed: i) The recruitment of DNMT by the miR-20a/AGO2 complex to HBV cccDNA needs to be confirmed; ii) the presence of miR-induced methylation machinery should be determined in non-neoplastic hepatocytes infected with HBV; and iii) strategies to circumvent the risk for hepatocellular carcinoma should be developed, considering the oncogenic potential of miR-17-92 (31).

In conclusion, the present study proposed that, in human hepatoma cells, miR-20a is loaded onto AGO2, which is then translocated into the nucleus to induce the methylation of $\mathrm{HBV}$ DNA, leading to the suppression of HBV replication.

\section{Acknowledgements}

Not applicable.

\section{Funding}

The present study was supported by the Seoul National University Bundang Hospital (grant no. 03-2008-005 to Dr Jin-Wook Kim).

\section{Availability of data and materials}

The datasets used and/or analyzed during the present study are available from the corresponding author on reasonable request.

\section{Authors' contributions}

IYM, ESJ, SHJ and JWK designed the study; IYM, JHC and JWC performed the experiments; IYM, JHC, JWC, ESJ, SHJ and JWK analyzed data. All authors contributed to the final manuscript. All authors read and approved the final manuscript.

\section{Ethics approval and consent to participate}

Not applicable.

\section{Patient consent for publication}

Not applicable.

\section{Competing interests}

The authors declare that they have no competing interests. 


\section{References}

1. Ginzberg D, Wong RJ and Gish R: Global HBV burden Guesstimates and facts. Hepatol Int 12: 315-329, 2018

2. Disease GBD, Injury I and Prevalence C: Global, regional and national incidence, prevalence and years lived with disability for 354 diseases and injuries for 195 countries, and territories, 1990-2017: A systematic analysis for the global burden of disease study. Lancet 392: 1789-1858, 2018.

3. Seeger C and Mason WS: Molecular biology of hepatitis B virus infection. Virology 479-480: 672-686, 2015.

4. Werle-Lapostolle B, Bowden S, Locarnini S, Wursthorn K, Petersen J,Lau G, Trepo C, Marcellin P, Goodman Z, Delaney WE IV, et al: Persistence of cccDNA during the natural history of chronic hepatitis B and decline during adefovir dipivoxil therapy. Gastroenterology 126: 1750-1758, 2004.

5. Lok AS, Zoulim F, Dusheiko G and Ghany MG: Hepatitis B cure: From discovery to regulatory approval. Hepatology 66: 1296-1313, 2017.

6. Gish RG, Given BD, Lai CL, Locarnini SA, Lau JY, Lewis DL and Schluep T: Chronic hepatitis B: Virology, natural history, current management and a glimpse at future opportunities. Antiviral Res 121: 47-58, 2015 .

7. Yuen MF, Chen DS, Dusheiko GM, Janssen HLA, Lau DTY, Locarnini SA, Peters MG and Lai CL: Hepatitis B virus infection. Nat Rev Dis Primers 4: 18035, 2018.

8. Levrero M, Pollicino T, Petersen J, Belloni L, Raimondo G and Dandri M: Control of cccDNA function in hepatitis B virus infection. J Hepatol 51: 581-592, 2009.

9. Volz T, Lutgehetmann M, Wachtler P, Jacob A, Quaas A, Murray JM, Dandri M and Petersen J: Impaired intrahepatic hepatitis B virus productivity contributes to low viremia in most HBeAg-negative patients. Gastroenterology 133: 843-852, 2007.

10. Pollicino T, Belloni L, Raffa G, Pediconi N, Squadrito G, Raimondo $G$ and Levrero M: Hepatitis B virus replication is regulated by the acetylation status of hepatitis B virus cccDNA-bound H3 and H4 histones. Gastroenterology 130: 823-837, 2006.

11. Belloni L, Pollicino T, De Nicola F, Guerrieri F, Raffa G, Fanciulli M, Raimondo G and Levrero M: Nuclear HBx binds the HBV minichromosome and modifies the epigenetic regulation of cccDNA function. Proc Natl Acad Sci USA 106: 19975-19979, 2009.

12. Koumbi L and Karayiannis P: The epigenetic control of hepatitis $B$ virus modulates the outcome of infection. Front Microbiol 6 : $1491,2016$.

13. Kim JW, Lee SH, Park YS, Hwang JH, Jeong SH, Kim N and Lee DH: Replicative activity of hepatitis B virus is negatively associated with methylation of covalently closed circular DNA in advanced hepatitis B virus infection. Intervirology 54: 316-325, 2011.

14. Zhang Y, Mao R, Yan R, Cai D, Zhang Y, Zhu H, Kang Y, Liu H, Wang J, Qin Y, et al: Transcription of hepatitis B virus covalently closed circular DNA is regulated by $\mathrm{CpG}$ methylation during chronic infection. PLoS One 9: e110442, 2014.

15. Guo Y, Li Y, Mu S, Zhang J and Yan Z: Evidence that methylation of hepatitis $B$ virus covalently closed circular DNA in liver tissues of patients with chronic hepatitis B modulates HBV replication. J Med Virol 81: 1177-1183, 2009.

16. Cullen BR: Transcription and processing of human microRNA precursors. Mol Cell 16: 861-865, 2004.

17. Jonas $\mathrm{S}$ and Izaurralde E: Towards a molecular understanding of microRNA-mediated gene silencing. Nat Rev Genet 16: 421-433, 2015.

18. Benetti R, Gonzalo S, Jaco I, Muñoz P, Gonzalez S, Schoeftner S, Murchison E, Andl T, Chen T, Klatt P, et al: A mammalian microRNA cluster controls DNA methylation and telomere recombination via Rbl2-dependent regulation of DNA methyltransferases. Nat Struct Mol Biol 15: 268-279, 2008.

19. Sinkkonen L, Hugenschmidt T, Berninger P, Gaidatzis D, Mohn F, Artus-Revel CG, Zavolan M, Svoboda P and Filipowicz W: MicroRNAs control de novo DNA methylation through regulation of transcriptional repressors in mouse embryonic stem cells Nat Struct Mol Biol 15: 259-267, 2008.

20. Khraiwesh B, Arif MA, Seumel GI, Ossowski S, Weigel D, Reski R and Frank W: Transcriptional control of gene expression by microRNAs. Cell 140: 111-122, 2010.

21. Wu L, Zhou H, Zhang Q, Zhang J, Ni F, Liu C and Qi Y: DNA methylation mediated by a microRNA pathway. Mol Cell 38: $465-475,2010$
22. Chellappan P, Xia J, Zhou X, Gao S, Zhang X, Coutino G, Vazquez F, Zhang $\mathrm{W}$ and Jin H: siRNAs from miRNA sites mediate DNA methylation of target genes. Nucleic Acids Res 38: 6883-6894, 2010.

23. Wendte JM and Pikaard CS: The RNAs of RNA-directed DNA methylation. Biochim Biophys Acta Gene Regul Mech 1860: 140-148, 2017.

24. $\mathrm{Hu} \mathrm{W}$, Wang $\mathrm{T}$, $\mathrm{Xu} \mathrm{J}$ and $\mathrm{Li} \mathrm{H}$ : MicroRNA mediates DNA methylation of target genes. Biochem Biophys Res Commun 444: 676-681, 2014.

25. Morris KV, Chan SW, Jacobsen SE and Looney DJ: Small interfering RNA-induced transcriptional gene silencing in human cells. Science 305: 1289-1292, 2004

26. Aravin AA, Sachidanandam R, Bourc'his D, Schaefer C, Pezic D, Toth KF, Bestor T and Hannon GJ: A piRNA pathway primed by individual transposons is linked to de novo DNA methylation in mice. Mol Cell 31: 785-799, 2008.

27. Watanabe T, Tomizawa S, Mitsuya K, Totoki Y, Yamamoto Y, Kuramochi-Miyagawa S, Iida N, Hoki Y, Murphy PJ, Toyoda A, et al: Role for piRNAs and noncoding RNA in de novo DNA methylation of the imprinted mouse Rasgrf1 locus. Science 332: 848-852, 2011

28. Park HK, Min BY, Kim NY, Jang ES, Shin CM, Park YS, Hwang JH, Jeong SH, Kim N, Lee DH and Kim JW: Short hairpin RNA induces methylation of hepatitis B virus covalently closed circular DNA in human hepatoma cells. Biochem Biophys Res Commun 436: 152-155, 2013.

29. Carmona S, Ely A, Crowther C, Moolla N, Salazar FH, Marion PL, Ferry N, Weinberg MS and Arbuthnot P: Effective inhibition of HBV replication in vivo by anti-HBx short hairpin RNAs. Mol Ther 13: 411-421, 2006.

30. Ota A, Tagawa H, Karnan S, Tsuzuki S, Karpas A, Kira S, Yoshida $\mathrm{Y}$ and Seto M: Identification and characterization of a novel gene, C13orf25, as a target for 13q31-q32 amplification in malignant lymphoma. Cancer Res 64: 3087-3095, 2004

31. Mendell JT: miRiad roles for the miR-17-92 cluster in development and disease. Cell 133: 217-222, 2008.

32. Jung YJ, Kim JW, Park SJ, Min BY, Jang ES, Kim NY, Jeong SH, Shin CM, Lee SH, Park YS, et al: c-Myc-mediated overexpression of miR-17-92 suppresses replication of hepatitis B virus in human hepatoma cells. J Med Virol 85: 969-978, 2013.

33. Ladner SK, Otto MJ, Barker CS, Zaifert K, Wang GH, Guo JT, Seeger $\mathrm{C}$ and King RW: Inducible expression of human hepatitis $B$ virus (HBV) in stably transfected hepatoblastoma cells: A novel system for screening potential inhibitors of HBV replication. Antimicrob Agents Chemother 41: 1715-1720, 1997.

34. Sohn JA, Litwin S and Seeger C: Mechanism for CCC DNA synthesis in hepadnaviruses. PLoS One 4: e8093, 2009.

35. Yan H, Zhong G, Xu G, He W, Jing Z, Gao Z, Huang Y, Qi Y, Peng B, Wang H, et al: Sodium taurocholate cotransporting polypeptide is a functional receptor for human hepatitis B and D virus. Elife 1: e00049, 2012.

36. Bowden S, Jackson K, Littlejohn M and Locarnini S: Quantification of HBV covalently closed circular DNA from liver tissue by real-time PCR. Methods Mol Med 95: 41-50, 2004.

37. Zhang Y, Li C, Zhang Y, Zhu H, Kang Y, Liu H, Wang J, Qin Y, Mao R, Xie Y, et al: Comparative analysis of $\mathrm{CpG}$ islands among HBV genotypes. PLoS One 8: e56711, 2013.

38. Aparicio O, Geisberg JV, Sekinger E, Yang A, Moqtaderi Z and Struhl K: Chromatin immunoprecipitation for determining the association of proteins with specific genomic sequences in vivo. Curr Protoc Mol Biol Chapter 21: Unit 21 23, 2005.

39. Nelson JD, Denisenko O and Bomsztyk K: Protocol for the fast chromatin immunoprecipitation (ChIP) method. Nat Protoc 1: 179-185, 2006.

40. Lian SL, Li S, Abadal GX, Pauley BA, Fritzler MJ and Chan EK: The C-terminal half of human Ago2 binds to multiple GW-rich regions of GW182 and requires GW182 to mediate silencing. RNA 15: 804-813, 2009.

41. Stoll-Becker S, Repp R, Glebe D, Schaefer S, Kreuder J, Kann M, Lampert F and Gerlich WH: Transcription of hepatitis B virus in peripheral blood mononuclear cells from persistently infected patients. J Virol 71: 5399-5407, 1997.

42. Niranjanakumari S, Lasda E, Brazas R and Garcia-Blanco MA: Reversible cross-linking combined with immunoprecipitation to study RNA-protein interactions in vivo. Methods 26: 182-190, 2002.

43. Kramer MF: Stem-loop RT-qPCR for miRNAs. Curr Protoc Mol Biol Chapter 15: Unit 15 10, 2011. 
44. Livak KJ and Schmittgen TD: Analysis of relative gene expression data using real-time quantitative PCR and the 2(-Delta Delta C(T)) method. Methods 25: 402-408, 2001.

45. Pfaffl MW, Horgan GW and Dempfle L: Relative expression software tool (REST) for group-wise comparison and statistical analysis of relative expression results in real-time PCR. Nucleic Acids Res 30: e36, 2002.

46. Castanotto D, Tommasi S, Li M, Li H, Yanow S, Pfeifer GP and Rossi JJ: Short hairpin RNA-directed cytosine $(\mathrm{CpG})$ methylation of the RASSF1A gene promoter in HeLa cells. Mol Ther 12: 179-183, 2005

47. Kim JW, Zhang YH, Zern MA, Rossi JJ and Wu J: Short hairpin RNA causes the methylation of transforming growth factor-beta receptor II promoter and silencing of the target gene in rat hepatic stellate cells. Biochem Biophys Res Commun 359: 292-297, 2007.

48. Kalantari R, Chiang CM and Corey DR: Regulation of mammalian transcription and splicing by Nuclear RNAi. Nucleic Acids Res 44: 524-537, 2016.

49. Ipsaro JJ and Joshua-Tor L: From guide to target: Molecular insights into eukaryotic RNA-interference machinery. Nat Struct Mol Biol 22: 20-28, 2015

50. Macfarlane LA and Murphy PR: MicroRNA: Biogenesis, function and role in cancer. Curr Genomics 11: 537-561, 2010.

51. Robb GB, Brown KM, Khurana J and Rana TM: Specific and potent RNAi in the nucleus of human cells. Nat Struct Mol Biol 12: 133-137, 2005.

52. Janowski BA, Huffman KE, Schwartz JC, Ram R, Nordsell R, Shames DS, Minna JD and Corey DR: Involvement of AGO1 and AGO2 in mammalian transcriptional silencing. Nat Struct Mol Biol 13: 787-792, 2006

53. Kim DH, Villeneuve LM, Morris KV and Rossi JJ: Argonaute-1 directs siRNA-mediated transcriptional gene silencing in human cells. Nat Struct Mol Biol 13: 793-797, 2006

54. Gagnon KT, Li L, Chu Y, Janowski BA and Corey DR: RNA factors are present and active in human cell nuclei. Cell Rep 6: 211-221, 2014

55. Nishi K, Nishi A, Nagasawa T and Ui-Tei K: Human TNRC6A is an Argonaute-navigator protein for microRNA-mediated gene silencing in the nucleus. RNA 19: 17-35, 2013.

56. Li LC: Chromatin remodeling by the small RNA machinery in mammalian cells. Epigenetics 9: 45-52, 2014.
57. Pontier D, Picart C, Roudier F, Garcia D, Lahmy S, Azevedo J, Alart E, Laudié M, Karlowski WM, Cooke R, et al: NERD, a plant-specific $\mathrm{GW}$ protein, defines an additional RNAi-dependent chromatin-based pathway in Arabidopsis. Mol Cell 48: 121-132, 2012.

58. Park IY, Sohn BH, Yu E, Suh DJ, Chung YH, Lee JH, Surzycki SJ and Lee YI: Aberrant epigenetic modifications in hepatocarcinogenesis induced by hepatitis B virus $\mathrm{X}$ protein. Gastroenterology 132: 1476-1494, 2007.

59. Okano M, Bell DW, Haber DA and Li E: DNA methyltransferases Dnmt3a and Dnmt3b are essential for de novo methylation and mammalian development. Cell 99: 247-257, 1999.

60. Zheng DL, Zhang L, Cheng N, Xu X, Deng Q, Teng XM, Wang KS, Zhang X, Huang J and Han ZG: Epigenetic modification induced by hepatitis $B$ virus $X$ protein via interaction with de novo DNA methyltransferase DNMT3A. J Hepatol 50: 377-387, 2009.

61. Liao JY, Ma LM, Guo YH, Zhang YC, Zhou H, Shao P, Chen YQ and Qu LH: Deep sequencing of human nuclear and cytoplasmic small RNAs reveals an unexpectedly complex subcellular distribution of miRNAs and tRNA 3' trailers. PLoS One 5: e10563, 2010.

62. Park CW, Zeng Y, Zhang X, Subramanian S and Steer CJ: Mature microRNAs identified in highly purified nuclei from HCT116 colon cancer cells. RNA Biol 7: 606-614, 2010.

63. Burroughs AM, Kawano M, Ando Y,Daub CO and Hayashizaki Y: pre-miRNA profiles obtained through application of locked nucleic acids and deep sequencing reveals complex 5'/3' arm variation including concomitant cleavage and polyuridylation patterns. Nucleic Acids Res 40: 1424-1437, 2012.

64. Bai B, Liu H and Laiho M: Small RNA expression and deep sequencing analyses of the nucleolus reveal the presence of nucleolus-associated microRNAs. FEBS Open Bio 4: 441-449, 2014.

65. Yang $\mathrm{HC}$ and $\mathrm{Kao} \mathrm{JH}$ : Persistence of hepatitis B virus covalently closed circular DNA in hepatocytes: Molecular mechanisms and clinical significance. Emerg Microbes Infect 3: e64, 2014.

This work is licensed under a Creative Commons Attribution-NonCommercial-NoDerivatives 4.0 International (CC BY-NC-ND 4.0) License. 